\title{
Viewpoints
}

\section{COVID-19 death disparities among international migrant workers of South Asian origin: A comparative study between the Gulf Cooperation Countries and Singapore}

\author{
Mohammad Sorowar Hossain ${ }^{1}$ (1) ${ }^{a}$, Shameema Ferdous ${ }^{2}$ (), Henrike Karim-Kos ${ }^{3}$ (0), Enayetur Raheem² (1) \\ ${ }^{1}$ Department of Emerging and Neglected Diseases, Biomedical Research Foundation; School of Environment and Life Sciences, Independent \\ University, ${ }^{2}$ Department of Emerging and Neglected Diseases, Biomedical Research Foundation, ${ }^{3}$ Princess Maxima Center for pediatric Oncology \& \\ Netherlands Comprehensive Cancer Organisation \\ Keywords: COVID, international migrant workers, mortality disparity, gulf states, migrant \\ https://doi.org/10.52872/001c.28351
}

\section{Journal of Global Health Economics and Policy}

Vol. 1, 2021

Globally, an estimated 169 million people are international migrant workers (IMWs). ${ }^{1}$ Regular low-skilled IMWs typically experience sparse access to adequate water, sanitation, and healthcare, and live in overcrowded dormitories with shared washrooms and kitchens. All these unhygienic conditions put them at greater risk of infection. IMWs have, therefore, a lower quality of life and bear a higher burden of mental health problems than the local population. ${ }^{2} \mathrm{Ar}$ guably, the vulnerability against COVID-19 is expected to be much worse for irregular or 'illegal' migrants who live under constant fear of apprehension and deportation. Although the number of irregular migrant workers is unknown, it is believed to be 30 to 50 million worldwide. ${ }^{3}$

Despite many health challenges confronted by IMWs, data on their health aspects are fragmented and limited worldwide. The scarcity of data impedes the formulation of international policy responses to address the health needs of IMWs. ${ }^{4}$ A few studies in the USA and UK have highlighted the disproportionate number of COVID-19 deaths among migrant populations and ethnicities. ${ }^{5}$

The Gulf States and Singapore provide an interesting grounds for comparison, because both have a large number of IMWs. Gulf Cooperation Council (GCC) comprises of six Arab states including Saudi Arabia, United Arab Emirates (UAE), Qatar, Bahrain, Oman and Kuwait that hosts around 35 million IMWs, representing $10 \%$ of the global migrant workers. ${ }^{1}$ Both settings (Singapore and GCC countries) have similarities in terms of economy (i.e. similar GDP per capita), destination of healthy and young adult international migrant workers mostly from South Asian countries who are often engaged in energy-intensive construction and domestic works. ${ }^{6-8}$ Besides, both sending and host countries are in the similar geographic region, sharing a wide concept of the 'Asian culture'. Therefore it would be in- teresting to explore the COVID-19 vulnerability (mortality) among IMWs between these two settings.

Extracting IMWs related data is challenging worldwide, particularly from Gulf countries due to of lack reliable data. It is relevant to mention that the United Nation provides international migrant stock estimates only; it does not provide data on recent migrant flows in or out of the country. ${ }^{9}$ The missing migrant project of International Organization of Migration (IOM) collects mortality data from various sources including NGOs, media reports, interviews and surveys of migrants. ${ }^{10}$ In this study, we collected data (estimated number of IMWs and COVID-19 related death cases) from various sources including foreign ministry report, traditional national mainstream media reports and reports generated by organizations working on IMWs and expatriate platform (see additional file). For instance, estimates of Bangladeshi migrant workers living in GCC countries were obtained from migrant related reputed organization, GLMM (Gulf Labour Markets and Migration), while mortality data was extracted from Refugee and Migratory Movements Research Unit (RMMRU), a well-known Bangladesh based NGO. ${ }^{11}$ Different sources for the same information were cross-checked for reliability. Latest death reports of IMWs in GCC states and Singapore included in this study were of December 2020 for Bangladesh and Sri Lanka, while Kerala (India) and Nepal were of September 2020.

Based on the publicly available data, we found that IMWs from South Asian origin died of COVID-19 disproportionately in the Gulf States as compared to Singapore (cumulative mortality/million: 278 vs 10 ) (Table 1 ). We found that in GCC countries, among nearly 8 million $(7,987,107)$ IMWs from Bangladesh, Kerala (India), Sri Lanka and Nepal, at least 2223 death cases were reported, while only 2 deaths were documented from 191,000 IMWs in Singapore. 
Table 1. Mortality disparities among international migrant workers in GCC countries and Singapore.

\begin{tabular}{|c|c|c|c|c|c|c|c|c|c|c|c|c|}
\hline & \multicolumn{3}{|c|}{ Bangladesh } & \multicolumn{3}{|c|}{ Kerala (India) } & \multicolumn{3}{|c|}{ Nepal } & \multicolumn{3}{|c|}{ Sri Lanka } \\
\hline & $\begin{array}{c}\text { Estimated } \\
\text { Population }\end{array}$ & $\begin{array}{c}\text { Total } \\
\text { deaths }\end{array}$ & $\begin{array}{l}\text { Deaths } \\
\text { /million }\end{array}$ & $\begin{array}{l}\text { Estimated } \\
\text { Population }\end{array}$ & $\begin{array}{c}\text { Total } \\
\text { deaths }\end{array}$ & $\begin{array}{l}\text { Deaths } \\
\text { /million }\end{array}$ & $\begin{array}{l}\text { Estimated } \\
\text { Population }\end{array}$ & $\begin{array}{c}\text { Total } \\
\text { deaths }\end{array}$ & $\begin{array}{l}\text { Deaths } \\
\text { /million }\end{array}$ & $\begin{array}{c}\text { Estimated } \\
\text { Population }\end{array}$ & $\begin{array}{c}\text { Total } \\
\text { deaths }\end{array}$ & $\begin{array}{l}\text { Deaths } \\
\text { /million }\end{array}$ \\
\hline $\begin{array}{l}\mathrm{GCC} \\
\text { countries }\end{array}$ & $4,151,607$ & 1254 & 302.1 & $1,900,000$ & 406 & 213.7 & $1,194,500$ & 474 & 396.8 & 741,000 & 89 & 120.1 \\
\hline $\begin{array}{l}\text { Saudi } \\
\text { Arabia }\end{array}$ & $2,000,000$ & 979 & 489.5 & 490,000 & 180 & 367.3 & 380,000 & $52^{* *}$ & ** & 135,000 & $6^{* *}$ & ** \\
\hline UAE & 710,000 & 130 & 183.1 & 830,000 & 118 & 142.2 & 300,000 & $36^{* *}$ & ** & 300,000 & $8^{* *}$ & $* *$ \\
\hline Oman & 680342 & 30 & 44.1 & 180000 & 24 & 133.3 & 17500 & * & & 26000 & $*$ & \\
\hline Qatar & 400,000 & 25 & 62.5 & 190,000 & 16 & 84.2 & 400,000 & $*$ & & 140,000 & * & \\
\hline Kuwait & 181,265 & 75 & 413.8 & 130,000 & 59 & 453.8 & 62,000 & $*$ & & 130,000 & 7 & $* *$ \\
\hline Bahrain & 180,000 & 15 & 83.3 & 80,000 & 9 & 112.5 & 35,000 & $*$ & & 10,000 & $*$ & \\
\hline Singapore & 152,000 & 2 & 13.2 & 26,000 & 0 & & 2,000 & 0 & & 11,000 & 0 & \\
\hline
\end{tabular}

* Data is not available; ** Incomplete data; See additional file for data sources 
Higher risk of severe clinical outcome of COVID-19 is strongly associated with older age (60 years and above) and comorbidities. However, despite being younger (median age $\sim 30-33$ years) and physically healthy migrant populations in both settings, South Asian migrants died disproportionately in GCC, notably in Saudi Arabia. ${ }^{7,8}$ As expected, because of poor living conditions, IMWs were disproportionately infected with the virus as compared to local populations in both settings. In Singapore, 93\% of all cases were reported among IMWs, while IMWs of Saudi Arabia comprised 76\% of infected cases. ${ }^{12,13}$

In GCC countries, employers are supposed to provide basic healthcare services to regular migrant workers. However, domestic workers and irregular migrants are largely ignored from healthcare insurance due to existing policy and regulations, although they comprise a significant proportion of IMWs in GCC countries. ${ }^{14}$ Migrant workers may fall victim to inherently problematic employer-worker relationship and could automatically become irregular ('illegal') in GCC countries. In such cases, the employers are responsible to report to the local police station for 'missing' migrants. An estimated $10-15 \%$ of IMWs are irregular migrants in GCC countries, who try to hide in fear of legal action. ${ }^{3}$ As a consequence, it is likely that irregular migrants and domestic workers suffering from COVID-19 complications would report to the hospital as much delay as possible. Perhaps, this delayed presentation might contribute to disproportionate mortality rates in GCC countries. Besides, cultural and linguistic barriers during evolving lockdown and curfew measures might have also contributed to delayed presentation. ${ }^{15}$

In contrast, Singapore has relatively less problems with the issue of irregular migrants because of transparent and proper implementation of immigration laws and regulations and recruiting process. ${ }^{16}$ For managing COVID-19 situation, Singapore took swift and transparent measures by setting up a multilingual communication strategy and onsite healthcare facility, making it accessible to all migrant workers. ${ }^{17}$ Even though, around $47 \%$ of all migrant workers $(152,000 / 323,0000)$ were infected, only 25 cases required ICU supports. ${ }^{12}$ This well-executed rapid responses might have contributed to lower mortality in Singapore.

In addition, higher prevalence of comorbidities resulting from adapted new lifestyle in GCC (consuming junk food and lack of physical activities) could also be a contribution factor for disproportionate deaths in GCC countries. A recent study found that IMWs had significantly higher risks of overweight/obesity, hypertension, and depression in GCC than non-migrants of the origin countries. ${ }^{7}$

International migrant related data has some inherent limitations. At the time of writing, data on gender, individual age, co-morbidities were not available. Therefore, ageand sex-specific adjustment of mortality rates are not presented in our analysis. Future studies should focus on generating good quality data from household surveys of IMWs in origin (sending) countries. Retrospective studies could also indicate mortality disparities of IMWs by estimating excess of deaths during COVID-19 pandemic. Interestingly, a recent study has suggested disproportionate deaths of
IMWs (over 71\% increase in expected mortality from historical trend) in the year of COVID-19 pandemic in a GCC country ( Kuwait), which is hosting a large number of South Asian IMWs. ${ }^{6}$ This finding seems consistent with our study. Therefore, a proper caution is needed while interpreting our study findings. However, taking all drawbacks into account, our study provides a strong evidence of disproportionate COVID-19 associated deaths among IMWs in GCC countries. Our findings can contribute to the future studies and developing international policy responses to protect the most vulnerable occupational migrant communities worldwide in times of crisis like the COVID-19 pandemic.

\section{ETHICS APPROVAL}

Not applicable

\section{FUNDING}

There was no funding for this project.

\section{AVAILABILITY OF DATA AND MATERIALS}

All used data are available within the article or as a supplementary material: https://joghep.scholasticahq.com/article/28351-covid-19-death-disparities-among-international-migrant-workers-of-south-asian-origin-a-comparati ve-study-between-the-gulf-cooperation-countries-and-s/ attachment/71514.pdf.

\section{AUTHOR CONTRIBUTIONS}

MSH conceived the idea, conducted the literature search and wrote the manuscript. HK formatted the table. SF, HK, ER provided suggestions on literature to include and made comments and edits to the manuscript. All authors were involved in drafting and revising critically for important intellectual content, approved the manuscript to be published and have agreed to be accountable for all aspects of the work.

\section{COMPETING INTERESTS}

The authors completed the ICMJE Unified Competing Interest form at (available upon request from the corresponding author), and declare no conflicts of interest.

\section{CORRESPONDENCE}

Mohammad Sorowar Hossain, PhD; Biomedical Research Foundation, Dhaka 1230, Bangladesh. Phone: +880-1963378441; sorowar.hossain@brfbd.org

Submitted: August 23, 2021 CET, Accepted: September 22, 2021 CET 
COVID-19 death disparities among international migrant workers of South Asian origin: A comparative study between the Gulf...

This is an open-access article distributed under the terms of the Creative Commons Attribution 4.0 International License (CCBY-4.0). View this license's legal deed at http://creativecommons.org/licenses/by/4.0 and legal code at http://creativecommons.org/licenses/by/4.0/legalcode for more information. 


\section{REFERENCES}

1. ILO. Labour Migration (Arab States). International Labour Organization (ILO). https://www.ilo.org/beiru t/areasofwork/labour-migration/lang--en/index.htm. Accessed September 21, 2021.

2. Hargreaves S, Rustage K, Nellums LB, et al. Occupational health outcomes among international migrant workers: a systematic review and metaanalysis. Lancet Glob Heal. 2019;7(7):e872-e882. doi:1 0.1016/S2214-109X(19)30204-9

3. Fargues P, Shah NM. Skilful Survival: Irregular Migration to the Gulf(Edited Volume) - GLMM. http s://gulfmigration.org/publications/book/. Accessed September 21, 2021.

4. Sweileh WM, Wickramage K, Pottie K, et al. Bibliometric analysis of global migration health research in peer-reviewed literature (2000-2016). BMC Public Health. 2018;18(1):1-18. doi:10.1186/s128 89-018-5689-x

5. Greenaway C, Hargreaves S, Barkati S, et al. COVID-19: Exposing and addressing health disparities among ethnic minorities and migrants. $J$ Travel Med. 2021;27(7):1-3. doi:10.1093/JTM/TAAA11 $\underline{3}$

6. Alahmad B, AlMekhled D, Odeh A, Albloushi D, Gasana J. Disparities in excess deaths from the COVID-19 pandemic among migrant workers in Kuwait. BMC Public Health. 2021;21(1):1668. doi:10.1 186/S12889-021-11693-W

7. Kuhn R, Barham T, Razzaque A, Turner P. Health and well-being of male international migrants and non-migrants in Bangladesh: A cross-sectional follow-up study. PLoS Med. 2020;17(3):e1003081. do $\mathrm{i}: 10.1371 /$ JOURNAL.PMED.1003081

8. Tan IB, Tan C, Hsu LY, et al. Prevalence and Outcomes of SARS-CoV-2 Infection Among Migrant Workers in Singapore. JAMA. 2021;325(6):584-585. do $\mathrm{i}: 10.1001 / J A M A .2020 .24071$
9. Mcdonald J. MIGRATION POLICY PRACTICE. http s://publications.iom.int/system/files/pdf/mpp29.pdf. Accessed September 21, 2021.

10. ILO. Labour Migration (Arab States). International Labour Organization (ILO). https://www.ilo.org/beiru t/areasofwork/labour-migration/lang--en/index.htm. Accessed September 21, 2021.

11. Siddiqui T, Billah M. Labour Migration From Bangladesh 2020. http://www.rmmru.org/newsite/w p-content/uploads/2021/03/Migration-Trends-Repor t-2020.pdf. Published 2020. Accessed September 21, 2021.

12. Measures to contain the COVID-19 outbreak in migrant worker dormitories. https://www.mom.gov.s $\mathrm{g} /$ newsroom/press-releases/2020/1214-measures-to-c ontain-the-covid-19-outbreak-in-migrant-worker-do rmitories. Accessed August 8, 2021.

13. Migrants Are Among The Worst Hit By COVID-19 In Saudi Arabia And Gulf Countries: Coronavirus Updates : NPR. https://www.npr.org/sections/coronav irus-live-updates/2020/05/05/850542938/migrants-ar e-among-the-worst-hit-by-covid-19-in-saudi-arabiaand-gulf-countries. Accessed August 8, 2021.

14. Rahman M. COVID-19 and Migrants in the GCC states: Challenges, responses and key lessons. http s://www.arabnews.com/node/1630246/middle-east. Published April 2021.

15. Alahmad B, Kurdi H, Colonna K, Gasana J, Agnew J, Fox MA. COVID-19 stressors on migrant workers in Kuwait: Cumulative risk considerations. BMJ Glob Heal. 2020;5(7):1-5. doi:10.1136/bmigh-2020-002995

16. Yue C. Foreign Labor in Singapore: Trends, Policies, Impacts, and Challenges. Discuss Pap. 2011;(December). https://www.econstor.eu/handle/10 419/126866.

17. Koh D. Migrant workers and COVID-19. Occup Environ Med. 2020;77(9):634-636. doi:10.1136/OEME D-2020-106626 


\section{SUPPLEMENTARY MATERIALS}

\section{Additional File 1: Data sources for IMWs and death cases for South Asian countries}

Download: https://joghep.scholasticahq.com/article/28351-covid-19-death-disparities-among-international-migrantworkers-of-south-asian-origin-a-comparative-study-between-the-gulf-cooperation-countries-and-s/attachment/ 71514.pdf 